L. Amaranath MD, Shahpour Esfandiari MD, John Lockrem MD, Michael Rollins MD

\title{
Epidural analgesia for total hip replace- ment in a patient with dilated cardiomyopathy
}

\begin{abstract}
A 69-year-old patient with severe impairment of left ventricular function secondary to dilated cardiomyopathy underwent a successful tolal hip replacement under epidural analgesia. Perioperative heart rare and mean arterial pressure were stable at an analgesic level up to the seventh thoracic dermatome, achieved with mepiva. caine two per cent with epinephrine. Asymptomatic pulmonary hypertension, occurring during the insertion of the femoral prosthesis, subsided spontaneously over the next twelve hours. The circulatory effects of epidural analgesia and their significance in a patient with dilated cardiomyopathy are discussed.
\end{abstract}

Although spinal and epidural anaesthesia have been successfully used in patients with cardiac disease, there is little information on the associated haemodynamic responses in patients with cardiomyopathy. ${ }^{1,2}$ Recently, we used epidural analgesia for a 69-year-old male with a past history of chronic alcoholism, who had clinical, electrocardiographic, echocardiographic and invasive haemodynamic

\section{Key words}

SURGERY: total hip replacement; ANAESTHETIC TECHNIQUES: epidural; HEART: dilated cardiomyopathy.

From the Departments of Anesthesiology, Surgical Intensive Care, and Cardiology, Cleveland Clinic Foundation, Cleveland, Ohio.

Supported in part by the Cleveland Clinic Research Foundation Grant 1444.

Address correspondence to: Dr. L. Amaranath, Cleveland Clinic Foundation, Division of Anesthesiology, 9500 Euclid Avenue, Cleveland, Ohio, 44106 findings of dilated (congestive) cardiomyopathy. ${ }^{3}$ We report and discuss here his circulatory responses during epidural analgesia for total hip replacement.

\section{Case report}

The patient, age 69 , was admitted for evaluation of severe chronic right hip pain and possible total hip replacement. One year earlier he had been in "clinical" congestive heart failure, at which time M-mode and two-dimensional echocardiography had suggested dilated cardiomyopathy secondary to chronic alcoholism; left ventricular ejection fraction was calculated as 0.3 , and the left ventricle and atrium were markedly dilated. Bed rest, salt restriction, digitalis, diuretics and vasodilators subsequently diminished the frequency and severity of congestive heart failure.

On admission, arterial pressure was 120/70 $\mathrm{mmHg}$, and heart rate 68 beats per minute. Cardiac rhythm was regular, with loud S3 and S4 sounds. The chest roentgenogram showed biventricular cardiomegaly and Kerley $B$ lines in the right lung base. The electrocardiogram showed normal sinus rhythm, left ventricular hypertrophy and non-specific ST-T wave changes. M-mode and two-dimensional echocardiography reconfirmed the diagnosis of dilated cardiomyopathy. It was also noted that all the chambers of the heart were grossly dilated and generally hypocontractile, while left ventricular ejection fraction was estimated as 0.15 . There were no valvular abnormalities. Cardiac catheterization showed mild to moderate coronary artery disease with severe left ventricular dysfunction. The right ventricular systolic/diastolic pressure ratio was $6: 1$.

Following digitalis, diuretic and vasodilator therapy, the clinical picture of bi-ventricular heart failure improved over the next two days. 
TABLE Haemodynamic data

\begin{tabular}{|c|c|c|c|}
\hline & $\begin{array}{l}\text { Heart rate } \\
\text { (beats/min) }\end{array}$ & $\begin{array}{l}\text { Arterial } \\
\text { pressure } \\
(\text { mean })(\mathrm{mmHg})\end{array}$ & $\begin{array}{l}\text { Right } \\
\text { atrial } \\
\text { pressure } \\
\text { (mean) (mmHg) }\end{array}$ \\
\hline Preoperative & 72 & 83 & 8 \\
\hline \multicolumn{4}{|l|}{ Intraoperative } \\
\hline Before femoral prosthesis* & $\begin{array}{l}76 \\
(70 \text { to } 80)\end{array}$ & $\begin{array}{l}80 \\
\text { (73 to } 86 \text { ) }\end{array}$ & $\begin{array}{l}10 \\
\text { (8 to } 12)\end{array}$ \\
\hline After femoral prosthesist & $\begin{array}{l}75 \\
(70 \text { to } 80)\end{array}$ & $\begin{array}{l}92 \\
(83 \text { to } 100)\end{array}$ & $\begin{array}{l}16 \\
\text { (12 to } 20)\end{array}$ \\
\hline \multicolumn{4}{|l|}{ Postoperative } \\
\hline 30 minutes & 84 & 97 & 8 \\
\hline 8 hours & 74 & 73 & 8 \\
\hline \multirow[t]{2}{*}{12 hours } & 84 & 76 & 8 \\
\hline & $\begin{array}{l}\text { Pulmonary } \\
\text { artery } \\
\text { pressure } \\
\text { (mean) }(\mathrm{mmHg})\end{array}$ & $\begin{array}{l}\text { Pulmonary } \\
\text { capillary } \\
\text { wedge } \\
\text { pressure } \\
\text { (mean) }(\mathrm{mmHg})\end{array}$ & $\begin{array}{l}\text { Cardiac } \\
\text { index } \\
\left(l \cdot \mathrm{min}^{-1} \cdot \mathrm{m}^{-2}\right)\end{array}$ \\
\hline Preoperative & 28 & 18 & 2.6 \\
\hline \multicolumn{4}{|l|}{ Intraoperative } \\
\hline Before femoral prosthesis* & $\begin{array}{l}30 \\
(24 \text { to } 34)\end{array}$ & - & - \\
\hline After femoral prosthesis $\dagger$ & $\begin{array}{l}45 \\
(34 \text { to } 58)\end{array}$ & - & - \\
\hline \multicolumn{4}{|l|}{ Postoperative } \\
\hline 30 minutes & 58 & 34 & 2.6 \\
\hline 8 hours & 36 & 15 & 2.9 \\
\hline 12 hours & 28 & 13 & 2.6 \\
\hline
\end{tabular}

*Values represent average and range of 6 measurements obtained at 5 -minute intervals. †Values represent average and range of 12 measurements obtained at 5-minute intervals.

Right radial and pulmonary arterial (Swan Ganz) catheters were placed before anaesthesia, for perioperative haemodynamic monitoring. Systemic arterial, right atrial and pulmonary arterial pressures were displayed continuously on a four-channel recorder. All pre- and post-operative cardiac output measurements (by thermodilution) and pulmonary capillary wedge pressures were recorded with the patient lying supine (Table). The mean pulmonary artery and capillary wedge pressures were measured within one minute of the determinations of cardiac output.

The patient was premedicated with intramuscular meperidine $50 \mathrm{mg}$ and hydroxyzine $50 \mathrm{mg}$, and a lumbar epidural catheter was inserted in the operating room. Epidural analgesia to the seventh thoracic segment (bilateral pin prick test) was achieved with two per cent mepivacaine $(20 \mathrm{ml})$ containing $1: 200,000$ epinephrine. Oxygen was given at a rate of $4 \mathrm{~L} / \mathrm{min}$ by nasal catheter. The patient was placed in the left lateral position and a cementless right total hip replacement was performed. Fluid replacement consisted of $1000 \mathrm{ml}$ whole blood and $200 \mathrm{ml}$ dextrose five per cent in 0.45 per cent $\mathrm{NaCl}$. The anaesthetic course was uneventful except for the onset of acute, asymptomatic pulmonary hypertension following the insertion of the femoral prosthesis (Table). We did not attempt treatment since 
there was no serious threat to overall circulatory function and serial arterial blood gas values were within normal limits ( $\mathrm{pH} 7.38, \mathrm{PCO}_{2} 45 \mathrm{mmHg}$, $\mathrm{PO}_{2} 98 \mathrm{mmHg}$ ).

Unfortunately, and despite repeated adjustments, a satisfactory tracing of pulmonary capillary wedge pressure was not obtained during surgery; we ascribe this to the lateral position of the patient. The catheter was therefore repositioned in the pulmonary artery and its site confirmed by visual inspection of the pressure tracing. ${ }^{4}$ Also, because of the non-steady state induced by operative blood loss, fluid replacement, and the development of pulmonary hypertension, we were unable to obtain accurate cardiac output measurements during surgery.

At the end of surgery, cutaneous analgesia had regressed to the tenth thoracic segment; bupivacaine 0.25 per cent $(12 \mathrm{ml})$ with $1: 200,000$ epinephrine was therefore injected into the epidural space for postoperative pain control. The patient was transferred to the surgical intensive care unit in satisfactory condition. Over the next one hour all evidence of cutaneous hypalgesia had disappeared, yet complete pain relief lasted for another eight hours. Significant elevations in pulmonary arterial and capillary wedge pressures continued into the immediate postoperative period, with a gradual return to the preoperative level during the next 12 hours (Table). In the intensive care unit, the patient received maintenance cardiac drugs, fluids, antibiotics and nasal oxygen. Postoperative chest roentgenograms and lung scans showed no pulmonary embolism. The remaining hospital course was uneventful and the patient was discharged ten days later.

\section{Discussion}

The incidence of dilated cardiomyopathy in chronic alcoholics is low but unpredictable, and usually occurs in patients already susceptible to myocardial damage for other reasons. ${ }^{5}$ The clinical picture of this progressive disease ranges from asymptomatic enlargement of all cardiac chambers, with minor electrocardiographic changes, to fulminant bi-ventricular heart failure. The cardinal feature is the presence of a greatly reduced left ventricular ejection fraction with a near-normal or low cardiac output. ${ }^{6}$ The right ventricular systolic pressure is usually three or more times the diastolic pressure. Further, these patients are prone to develop pulmonary hypertension and embolism.

Our patient satisfied the clinical and haemodynamically-measured criteria for a diagnosis of dilated cardiomyopathy. Despite a nearly normal cardiac output, the left ventricular ejection fraction had been progressively reduced from 0.3 one year previously to 0.15 at the time of surgery. Preoperative preparation had emphasized detailed haemodynamic monitoring and optimum doses of diuretics, vasodilators and digitalis.

The principles of therapy in cardiomyopathy are based on efforts to decrease both preload and afterload with diuretics and vasodilators respectively, and to stimulate the hypodynamic heart with inotropic agents. ${ }^{6}$ The aim of afterload reduction is to lessen the work required of the failing heart, by lowering peripheral vascular resistance and hence arterial pressure. Usually, this also leads to peripheral pooling of blood and thus to a reduced venous return (preload) to the left ventricle. Cardiac output is therefore increased while the heart's intrinsic contractile state is unchanged ${ }^{6}$

Epidural analgesia substantially reduces peripheral vascular resistance (afterload), and increases vascular distensibility in the anaesthetized areas. Consequently, the left ventricular filling pressure (preload) is also reduced. However, the net effect on cardiac output and arterial pressure depends on the segmental height of sympathetic blockade, on the rapidity of onset of analgesia, and on the vascular absorption of local anaesthetic and added epinephrine. In normovolemic volunteers, epidural block to the fourth and fifth thoracic segments with epinephrine - containing local anaesthetics generally reduces diastolic and mean arterial pressures; but there is an equivalent rise in cardiac output.? Higher levels of neuronal blockade, developing rapidly, can reduce systolic pressure precipitously, secondary to a severe reduction in venous return and cardiac output. However, this can be countered by administering vasopressors with mixed alpha and beta adrenergic properties (e.g., methamphetamine (Methedrine), or ephedrine). ${ }^{7}$

With spinal analgesia, the vasodilation in the anaesthetized segments, and associated large reduction in total peripheral resistance and arterial pressure, occur without concomitant increase in cardiac 
output. Apparently, this difference is due primarily to a more rapid onset of sympathetic blockade and incomplete circulatory adjustment. ${ }^{\text {? }}$

Although there is little experience of the likely effects of regional blockade in patients with cardiomyopathy, we selected epidural analgesia because it produces a relatively slow sympathetic blockade and decrease in peripheral vascular resistance. Wc assumed that an induced reduction in afterload and preload would benefit cardiac function, and favoured the addition of 1:200,000 epinephrine to the local anaesthetic solution as much for the betaadrenergic inotropic effect as for the increased duration of analgesia or lessened vascular absorption of mepivacaine. ${ }^{8}$ Although we were unable to obtain intraoperative pulmonary capillary wedge pressure and cardiac output readings, we believe that the circulatory effects of epidural block contributed to a relatively benign operative and postoperative course.

The occurrence of asymptomatic pulmonary hypertension requires explanation. While no clinical problems were encountered following insertion of the femoral prosthesis, transient increases in mean pulmonary arterial pressure, ranging from 2 to $4 \mathrm{mmHg}$, have been noted at this time, during both epidural and general anaesthesia. ${ }^{9}$ In healthy patients, these elevations gradually subside to normal. Efflux of tissue thromboplastic products from the medullary canal of the femur has been implicated, as have micro air emboli. ${ }^{10}$ This patient already had mild pulmonary hypertension (Table) and such severe cardiomyopathy that a rise in pulmonary artery pressure might be more pronounced following minor pulmonary embolization. " Preoperative medication could have explained the absence of tachypnoea and hyperventilation, expected with so acute and severe pulmonary hypertension. ${ }^{12}$ Similarly, the lack of an hypoxic response to impaction of the femoral prosthesis might have been due to intraoperative oxygen supplementation.

Another explanation for the increased pulmonary artery pressure was a worsening of pre-existing bi-ventricular failure, as a result of relative fluid overload. However, the dramatic rise less than a minute after insertion of the femoral prosthesis and the gradual, spontaneous recovery argue against this.

In summary, while clinical experience with regional blockade for patients with cardiomyopathy is limited, the epidural technique described offers potential advantages in selected cases, in that it satisfies, by pharmacological means, most of the principles recommended by cardiologists for the overall management. Disadvantages include technical difficulty in achieving satisfactory block, the possible hazard of local anacsthetic toxicity and the rapid onset of a high sympathetic block.

\section{Acknowledgement}

We are indebted to Dr. Ronald A. Millar for his assistance.

\section{References}

1 Kaplan JA, Dunbar RW. Anesthesia for noncardiac surgery in patients with cardiac disease. In Kaplan JA, ed. Cardiac Anesthesia, Grune and Stratton (1979) 377-89.

2 Hilgenberg JC. Cardiomyopathies. In Stoelting RK, Dierdorf SF, eds. Anesthesia and Co-Existing Disease. Churchill Livingstone Inc. (1983) 129-33.

3 Gaasch WH, Zile MR. Evaluation of myocardial function in cardiomyopathic states. Prog Cardiovascular Diseases 1983; 27: 115-32.

4 Civetta JM. Pulmonary artery catheter insertion. $\mathrm{Ch}$ 2, pp. 21-71. In: The Pulmonary Artery Catheter. Ed. Spring, C.L. Baltimore University Park Press, 1983.

5 Regan TJ. Alcoholic cardiomyopathy. Prog Cardiovascular Diseases 1984; 27: 141-52.

6 Johnson RA, Palacios I. Dilated cardiomyopathies of the adult. N Engl J Med 1982; 307: 1051-8.

7 Bromage PR. Epidural Analgesia. W.B. Saunders Co., 1978.

8 Bonica JJ, Akamatsu TJ, Berges PU, Morikawa $K$, Kennedy $W F$. Circulatory effects of peridural block. II. Effects of epinephrine. Anesthesiology 1971; 34: 514-22.

9 Modig J, Malberg P. Pulmonary and circulatory reactions during total hip replacement surgery. Acta Anaesthesiol Scand 1975; 19: 219-37.

10 Andesen $K H$. Air aspirated from the venous system during total hip replacement. Anaesthesia 1983; 38: 1175-8.

11 Alpert JS, Godtfreden J, Ockene IS, Anas J, Dalen $J E$. Pulmonary hypertension secondary to minor pulmonary embolism. Chest 1978; 73: 795-7. 
12 Dexter $L$, Alpert JS, Dalen JE. Pulmonary embolism, infarction and acute cor pulmonale. In: Hurst JE, Ed. The Heart, McGraw-Hill Book Co (1982) $1227-42$.

\section{Résumé}

Un patient âgé (69 ans) dont la fonction du ventricule gauche est sévèrement atteinte suite à une cardiomyopathie a subi avec succès une chirurgie de remplacement de la hanche sous analgésie épidurale. La fréquence cardiaque et la pression artérielle moyenne péri-opératoire étant stables à un niveau d'analgésie égale au septième dermatome thoracique. La mépivacaine deux pour cent avec épinéphrine fut utilisée. Une hypertension pulmonaire asymptomatique est survenue durant l'insertion de la prothèse fémorale revenant spontanément à la normale au cours des douzes prochaines heures. Les effets circulatoires de l'analgésie épidurale et leur importance chez un patient atteint de cardiomyopathie sont discutés. 